\title{
Manicômio Judiciário e Agentes Penitenciários: entre Reprimir e Cuidar
}

\author{
Rodrigo Padrini Monteiro ${ }^{1}$ \\ ${ }^{1}$ Pontifícia Universidade Católica, MG, Brasil.
}

\author{
José Newton Garcia Araújo ${ }^{1}$ \\ ${ }^{1}$ Pontifícia Universidade Católica, MG, Brasil.
}

Resumo: Os manicômios judiciários são instituições destinadas a acolher pessoas que cometem crimes e que, por motivo de doença ou deficiência mental, são consideradas inimputáveis, também tratadas como "louco infrator" ou "paciente judiciário". O presente artigo, baseado em pressupostos críticos da Psicologia do Trabalho, discute resultados obtidos a partir de uma pesquisa de mestrado em um manicômio judiciário de Minas Gerais. O estudo buscou compreender a atividade dos agentes penitenciários, responsáveis por garantir a ordem e a segurança do estabelecimento e de todos os indivíduos ali presentes. Constatou-se que sua atividade não se restringe à segurança, mas que abrange o cuidado, o envolvimento afetivo e a preocupação com os indivíduos custodiados naquela instituição. Se o trabalho de agente penitenciário é socialmente marginalizado, verificou-se que ele é valorizado pelos sujeitos que o executam, mesmo que estes se deparem com a ambivalência inerente à natureza do manicômio judiciário. Entre a prescrição de reprimir e o apelo a cuidar, os agentes enfrentam uma realidade marcada pelo duplo sofrimento do paciente judiciário: o rótulo da loucura e a privação da liberdade.

Palavras-chave: Sistema Prisional, Loucura, Psicologia do Trabalho, Manicômio Judiciário, Agente Penitenciário.

\section{Judicial Asylums and Prison Guards: Between Repressing and Caring}

\begin{abstract}
The judicial asylums are institutions designed to accommodate individuals who commit crimes and who, because of illness or mental disability, are considered not imputable, also treated as "judicial patient" or "crazy offender". This article, based on critical assumptions of work psychology, discusses results obtained from a master's research carried out in a judicial asylum of Minas Gerais. The study searched to understand the activity of the prison guards, responsible for ensuring the order and safety of the establishment and of all individuals present there. It was found that their activity is not restricted to security, but that it includes care, affective involvement and concern with the individuals guarded in that institution. If the work of penitentiary agent is socially marginalized, we could verify that it is valued by the subjects who execute it, even if they are faced with the ambivalence inherent in the nature of the judiciary asylum. Between the prescription of repression and the call to care, the agents face a reality marked by the double suffering of the "judicial patient": the label of madness and the deprivation of freedom.
\end{abstract}

Keywords: Prison System, Madness, Work Psychology, Judicial Asylum, Prison Guard. 


\title{
Manicomio Judicial y Agentes Penitenciarios: entre Reprimir y Cuidar
}

\begin{abstract}
Resumen: Los manicomios judiciales son instituciones destinadas a acoger a personas que cometen crímenes y que, por motivo de enfermedad o discapacidad mental, son consideradas inimputables, también tratadas como "loco infractor" o "paciente judicial". El presente artículo, basado en supuestos críticos de la psicología del trabajo, discute resultados obtenidos a partir de una investigación de maestría en un manicomio judicial de Minas Gerais. El estudio buscó comprender la actividad de los agentes penitenciarios, responsables de garantizar el orden y la seguridad del establecimiento y de todos los individuos allí presentes. Se constató que su actividad no se restringe a la seguridad, sino que abarca el cuidado, la implicación afectiva y la preocupación con los individuos custodiados en aquella institución. Si el trabajo de agente penitenciario es socialmente marginado, se ha comprobado que es valorado por los sujetos que lo ejecutan, aunque éstos se enfrenten a la ambivalencia inherente a la naturaleza del manicomio judicial. Entre la prescripción de reprimir y el llamamiento a cuidar, los agentes enfrentan una realidad marcada por el doble sufrimiento del "paciente judicial": el rótulo de la locura y la privación de la libertad.
\end{abstract}

Palabras clave: Sistema Penitenciario, Locura, Psicología del Trabajo, Manicomio Judicial, Agente Penitenciario.

\section{Introdução}

No mundo do trabalho formal e informal, encontramos atividades e ofícios com diferentes graus de visibilidade, prestígio e reconhecimento social. Ao mesmo tempo, em determinados ambientes laborais, deparamo-nos especificamente com atividades que se encontram na parte inferior de uma suposta "escala moral do trabalho", como afirma Lhuilier (2014), ao referir-se a profissionais que se ocupam, por exemplo, do lixo, da faxina, dos cemitérios ou com trabalhos que envolvem doenças, morte, loucura, velhice, marginalidade e deficiência, entre outras.

Nesse patamar, localizamos duas instituições nas quais, segundo a autora, tem lugar o "negativo psicossocial”, noção referente a ocupações conceituadas originalmente por Hughes (1996) como "trabalho sujo". Trata-se de atividades pouco valorizadas socialmente ou que permanecem nos bastidores, pois ocorrem junto a estratos marginais da sociedade ou de populações confinadas em instituições totais, como prisões e manicômios. Neste estudo, vamos abordar justamente uma instituição que abriga esse negativo psicossocial, em meio a duas representações sociais relativas ao crime e à loucura, ou seja, o manicômio judiciário.

Os Hospitais de Custódia e Tratamento Psiquiátrico (HCTP), originalmente chamados de manicô- mios judiciários, representam a "superposição complexa de dois modelos de intervenção social: o modelo jurídico-punitivo e o modelo psiquiátrico-terapêutico" (Carrara, 1998, p. 46). Eles são destinados, particularmente, a receber pessoas que cometem crimes e que, por motivo de doença ou deficiência mental, são consideradas inimputáveis, ou seja, indivíduos isentos de pena, por não serem capazes de compreender o caráter ilícito do delito praticado (Conselho Federal de Psicologia, 2015; Diniz, 2013).

No Brasil, de acordo com o Art. 26 do Código Penal,

é isento de pena o agente que, por doença mental ou desenvolvimento mental incompleto ou retardado, era, ao tempo da ação ou da omissão, inteiramente incapaz de entender o caráter ilícito do fato ou de determinar-se de acordo com esse entendimento (Decreto-Lei no 2.848, 1940).

Nesse caso, aplica-se judicialmente a medida de segurança, seja ela de internação, quando há reclusão em hospital de custódia e tratamento psiquiátrico, ou de tratamento ambulatorial, quando não há internação, cabendo ao aparelho médico-científico envolvido o diagnóstico, o tratamento e a avaliação.

Para Carrara (2010), esses estabelecimentos articulam, "duas das realidades mais deprimentes das 
sociedades modernas - $\mathrm{o}$ asilo de alienados e a prisão" (p. 17), estando presentes aí dois componentes que aparentemente se opõem: o que cuida e recupera, e o que reprime e segrega. Quase dois séculos após o seu surgimento, a existência do manicômio judiciário se fundamenta, ainda hoje, na relação construída entre crime e doença mental, segundo as premissas da periculosidade e da proteção social.

Pretendemos discutir aqui alguns resultados de uma pesquisa de mestrado realizada no ano de 2017, intitulada "O dom de ver atrás do morro: a atividade de agentes de segurança penitenciários em um manicômio judiciário de Minas Gerais", apresentada ao Programa de Pós-Graduação em Psicologia da Pontifícia Universidade Católica de Minas Gerais, em fevereiro de 2018. Desenvolvido no Hospital Psiquiátrico e Judiciário Jorge Vaz (HPJJV), localizado no município de Barbacena, criado em 1927 (Decreto no 7.471, 1927) e inaugurado em 1929, o estudo teve como objetivo compreender a atividade dos agentes penitenciários, neste estabelecimento.

Nesta instituição, que guarda parte da história da loucura no Brasil, conhecemos, então, paradoxalmente, um trabalho que não se restringe à segurança e à garantia da ordem, mas que abrange o cuidado e o envolvimento afetivo com os indivíduos custodiados. Em nossa investigação, adotamos os pressupostos teóricos da Psicologia do Trabalho e discutimos alguns aspectos retirados da pesquisa de campo, tais como: a escolha da profissão; a representação da atividade; a ambivalência institucional; e os impactos do trabalho sobre os agentes.

Busca-se aqui trazer novos conhecimentos que contribuam para superar a escassez de estudos científicos sobre os manicômios judiciários e, principalmente, sobre os trabalhadores dessas instituições. Além disso, tentamos enfatizar a importância do trabalho como centro de desenvolvimento psicológico e social, interessando-nos em conhecer os enigmas da atividade, na palavra de quem os experimenta: o trabalhador.

\section{Prisões e agentes de segurança penitenciários}

O estudo das políticas penitenciárias e da origem das prisões mostra significativas mudanças, ao longo dos séculos, na ideia de justiça e da finalidade das penas privativas de liberdade, além de outros métodos punitivos. Como aponta Foucault (2014), evoluímos de um sistema que previa e sancionava o uso de penas destinadas ao castigo, suplício e afirmação do poder soberano, para um sistema disciplinar que adota o princípio da correção e da ressocialização do indivíduo preso, como forma de prevenir crimes futuros, além da delinquência e da transgressão das normas vigentes. Em nossa sociedade ocidental, no entanto, a prisão ainda se mantém como mecanismo punitivo predominante, em detrimento de outras medidas disciplinares.

No Brasil, a Lei de Execução Penal (Lei no $7.210,1984)$, baseada na segregação como dispositivo de sanção e recuperação moral dos indivíduos, não só produz o encarceramento em massa e a criação de novos presídios, como parece descartar demais alternativas (IPEA, 2015), fazendo com que a função ressocializadora das prisões seja frequentemente questionada.

O Brasil ocupa, atualmente, o terceiro lugar no ranking dos dez países com maior população prisional do mundo, ultrapassando a marca de 700 mil presos em 1.449 estabelecimentos penais (Brasil, 2017). Nesse contexto, observa-se um sistema penal que não põe em prática o mínimo que preconiza, em termos legais, e que apresenta um quadro de graves deficiências estruturais e condições desumanas de custódia (Ministério Público, 2016).

Compondo parte relevante da população carcerária brasileira, Minas Gerais é o segundo estado com maior população prisional do país, com 68.354 detentos - $58 \%$ destes são provisórios, sem condenação - e capacidade para apenas 36.556, registrando um déficit de 31.798 vagas (Brasil, 2017). De acordo com Câmara (2017), esse quantitativo de presos ultrapassou os 70 mil, em 2017, distribuídos em 200 unidades prisionais, administradas pela Secretaria de Estado de Administração Prisional (SEAP) (Decreto no 47.087, 2016; SEAP, 20171), classificadas, de acordo com o Regulamento de Normas e Procedimentos (SEAP, 2016), da forma apresentada no Quadro 1.

Quanto aos profissionais responsáveis por manter esse sistema em funcionamento, Oliveira, Ribeiro e Bastos (2015) afirmam que o sistema prisional mineiro expandiu seu número de trabalhadores, no período de

${ }^{1}$ Secretaria de Estado de Administração Prisional - SEAP. (2017). Gráficos: Evolução unidades prisionais. Mensagem recebida por: <rodrigopadrini@gmail.com>em 04 de outubro de 2017. 


\section{Quadro 1}

Quantidade de estabelecimentos penais, por tipo, em Minas Gerais.

\begin{tabular}{|lc|}
\hline Tipo & Quantidade \\
\hline Centro de Remanejamento do Sistema Prisional & 5 \\
Presídios & 176 \\
Complexo Penitenciário & 6 \\
Penitenciárias & 15 \\
Hospitais de Custódia e Tratamento Psiquiátrico e Centros de Apoio Médico e & 3 \\
Pericial & 2 \\
Casas de Albergado & 2 \\
Centros de Referência da Gestante Privada de Liberdade & 1 \\
Total & 208 \\
\hline
\end{tabular}

Fonte: Elaborado pelo autor, a partir de dados disponíveis no site da Secretaria de Estado de Administração Prisional, em dezembro de 2017.

2003 a 2014. De acordo com a SEAP (2017) $)^{1}$,em julho de 2017, o sistema mineiro contava com aproximadamente 22.960 mil funcionários, sendo cerca de 20 mil agentes penitenciários e os demais divididos entre servidores administrativos, técnicos e gestores.

$\mathrm{O}$ agente penitenciário é frequentemente considerado a personificação do Estado, na aplicação de suas sentenças, sendo personagem fundamental no cotidiano da prisão. Geralmente identificado como responsável pelo encarceramento e pela violência, no interior dos presídios, ele também é, por outro lado, acometido por adoecimentos, direta ou indiretamente relacionados ao trabalho, tendo mesmo se tornado objeto de pesquisas, principalmente, nas últimas duas décadas (Bezerra; Assis, \& Constantino, 2016), ainda que, segundo Oliveira, Silva Junior, Costa e Araújo (2017), sejam raros os estudos sobre o seu trabalho. Quanto à atuação específica dos agentes nos manicômios judiciários, sujeitos de nosso estudo, Pacheco (2011) confirma que, no Brasil, há um número bastante reduzido de pesquisas sobre eles, assim como sobre os estabelecimentos em que atuam.

Em Minas Gerais, a carreira de Agente de Segurança Penitenciário, apesar de já existir previamente, foi regulamentada em julho de 2003 (Lei no 14.695, 2003). Trata-se de uma categoria que contava com menos de 600 trabalhadores, em 1999 (SINDASP, 2017), e que contabiliza hoje, aproximadamente, 20 mil. Destes, menos de 250 atuam nas três unidades de perícia e atendimento médico, como os HCTP e Cen- tros de Apoio Médico Pericial, no estado. Os dados foram obtidos junto à Diretoria de Gestão de Pessoas da SEAP, em 17 de novembro de 2017. Para o total informado, foram considerados 50 agentes no Centro de Apoio Médico Pericial (CAMP), 67 no Hospital de Toxicômanos Padre Wilson Vale da Costa (HTPWVC) e 119 agentes no Hospital Psiquiátrico e Judiciário Jorge Vaz (HPJJV), no qual foi realizada esta pesquisa. É sobre a atividade destes últimos que nos deteremos, em nossa análise.

Além da função conhecida, supostamente simplificada, de abrir e fechar cadeados e impedir que os presos deixem a prisão, o agente tem inúmeras e complexas atividades, de acordo com o território, a estrutura física da unidade prisional e a quantidade de presos junto aos quais ele atua. Suas atribuições básicas são: garantir a ordem e a segurança, no interior dos estabelecimentos penais; desempenhar ações de vigilância interna e externa desses locais; exercer operações de escolta e custódia de presos.

Apesar de executar e promover ações de segurança que, ao mesmo tempo, garantam o acesso do preso às atividades de ressocialização, não é previsto que $o$ agente se dedique diretamente a essa ressocialização, prevista na Lei de Execuções Penais - LEP (Lei $\left.\mathrm{n}^{\circ} 7.210,1984\right)$, o que deixa clara a ênfase na vigilância, segurança e disciplina, em seu ofício. Verificamos, em estudos documentais, que a formação dos agentes se detém, predominantemente, no âmbito jurídico e disciplinar, cabendo-lhe, no plano da ressocialização, apenas fornecer as condições para que os profissio- 
nais técnicos e de ensino superior se ocupem da recuperação do detento (Minas Gerais, 2013). No entanto, como veremos adiante, mesmo sem essa formação, ele tem um papel fundamental no cuidado e no tratamento humanizado do detento.

\section{Loucos criminosos e manicômios judiciários}

Sobre a origem de estabelecimentos destinados especialmente aos loucos, Foucault (1972) assinala o surgimento de uma série de casas para recebê-los, com exclusividade, ainda no século XVIII. Isso ocorreu em todo o continente europeu, em meio a mudanças sociais, econômicas, políticas e filosóficas, o que permitiu emergir, pouco a pouco, a noção moderna de loucura. Na passagem do século XVIII ao século XIX, o espaço dedicado aos loucos se transformou em um espaço médico e, segundo Pessotti (2006), o século XIX foi "a época de maior florescimento da teoria e da terapêutica da loucura” (p. 113). Afinal, a emergente psiquiatria do período possibilitou, ao longo do século XIX e início do século XX, o desenvolvimento de um conhecimento médico e científico que identificou, classificou, organizou, sistematizou e interpretou a loucura.

No Brasil, o Estado apoiou e organizou, assim como nos países europeus, "campanhas de moralização e higienização da população, através da ação conjunta dirigida pela assistência social, pela medicina e filantropia" (Azevedo, 2014, p.39). Nesse contexto, o surgimento da figura do louco criminoso e a demanda por um estabelecimento para confiná-lo acompanhou a discussão sobre as distinções entre culpa ou inocência, ao mesmo tempo em que os aparelhos jurídicos, policiais e médicos se articulavam para lidar com essa "nova espécie". Com as novas categorias médicas, no século XIX, tomou-se a loucura como algo invisível, imprevisível e perigoso, já que, também nos indivíduos ditos normais, ela poderia estar adormecida, como condição permanente e hereditária.

Compreendendo-se a delinquência - na figura do louco, do criminoso, ou em sua união - como um inimigo interno da sociedade que buscava o progresso, uma série de intervenções físicas, sociais e políticas estariam justificadas. Esses indivíduos, "muito inocentes para ficarem nas prisões, mas muito perversos para ficarem no hospício" (Carrara, 2010, p. 153), deveriam ter outra instituição de confinamento.
Apesar de já existirem na Inglaterra e nos Estados Unidos, por exemplo, foi em 1903 (Decreto $\mathrm{n}^{\circ} 1.132$, 1903), através da legislação que marca a reorganização e a regulamentação da assistência aos alienados, que o Brasil estabeleceu que cada estado da União deveria concentrar recursos para construir manicômios judiciários.

Dessa forma, os criminosos loucos que, até o código penal de 1890, eram entregues às suas famílias ou internados em hospícios "comuns", segundo a decisão do juiz responsável, teriam o seu destino vinculado a uma instituição específica.

Assim, entre discursos sobre um determinismo biológico da índole criminosa e argumentos sobre o condicionamento social e cultural da liberdade individual, surgiria, quase 20 anos depois, o primeiro estabelecimento desse gênero, no país e na América Latina, o Manicômio Judiciário do Rio de Janeiro (Carrara, 1998).

Apesar de termos assistido, no Brasil, a partir da segunda metade do século $\mathrm{XX}$, a um movimento político e social conhecido como "luta antimanicomial" ou "reforma psiquiátrica" (Lei no 10.216, 2001), marco que redirecionou o modelo de assistência em saúde mental, sabe-se que os manicômios judiciários permaneceram excluídos desse processo. $\mathrm{E}$ mesmo em meio a iniciativas da sociedade civil e de atores governamentais, no sentido de substituir os manicômios por alternativas terapêuticas, os HCTP "tiveram, na década de 2000, o maior crescimento, em 90 anos de história: de 2000 a 2010, foi construído $1 / 4$ dos manicômios judiciários brasileiros" (Diniz, \& Brito, 2016, p. 114).

De acordo com o Ministério da Saúde (Brasil, 2014), havia 29 estabelecimentos dessa natureza no país, em 2014, e seis alas de tratamento psiquiátrico em presídios ou penitenciárias, com uma população total de, pelo menos, 4.500 pessoas acauteladas.

Em Minas Gerais, três estabelecimentos podem ser caracterizados como um HCTP, categorizados, de acordo com a legislação estadual, como unidades prisionais de perícia e atendimento médico (Decreto No 47.087, 2016): o CAMP, em Ribeirão das Neves; o HTPWVC, em Juiz de Fora; e o HPJJV, localizado em Barbacena.

Nestas instituições, de um lado, agentes são responsáveis por garantir a ordem e a segurança do estabelecimento e de todos os internos; de outro, profissionais de ensino técnico e superior são responsáveis 
por cuidar, tratar, avaliar e acompanhar os presos, garantindo a sua saúde e os seus direitos, enquanto cidadãos, visando à sua recuperação.

Um HCTP possui, em síntese, três finalidades: acompanhar e tratar pacientes em cumprimento de medida de segurança, oferecer tratamentos psiquiátricos temporários e realizar exames periciais específicos de sanidade mental, cessação de periculosidade ou de dependência toxicológica.

Em Minas Gerais, tais instituições, assim como suas equipes de profissionais, são geridas pela administração prisional estadual, na figura da SEAP, e não pela gestão de saúde. Assim, os HCTP compõem, junto com prisões e penitenciárias, o sistema prisional mineiro.

Os manicômios judiciários se enquadram, assim como as prisões "tradicionais", no que Goffman (2015) considerou como "instituições totais", ou seja, locais onde grande número de pessoas, em condição semelhante, vive separado da sociedade.

Esses manicômios estão na contramão da política antimanicomial, que prevê a internação em estabelecimentos com características como as citadas acima, como último recurso, ou seja, apenas quando os dispositivos extra-hospitalares se mostrarem de todo insuficientes.

Na prática, conforme duas publicações recentes do Conselho Federal de Psicologia (2015; 2016), o que se observa são as condições precárias dos HCTP e das alas psiquiátricas, no território brasileiro, e o atual quadro de violação de direitos e desrespeito à política nacional de saúde mental. Segundo o Conselho Regional de Medicina de São Paulo (CREMESP, 2013), o cumprimento de medidas de segurança nos hospitais de custódia do país frequentemente os transforma em prisões perpétuas, considerando-se a aliança entre descaso, abandono, falta de estrutura, ausência de consenso jurídico e carência de uma rede de dispositivos substitutivos.

\section{Uma análise psicológica da atividade no campo da segurança}

Para esta pesquisa, como já foi dito, utilizamos referenciais teóricos, basicamente, do campo que se convencionou chamar "clínicas do trabalho" (Lima, 2011), reunidas numa abordagem psicológica que mantém o seu foco de análise e de intervenção na atividade e nos trabalhadores, adotando uma perspectiva crítica e compreensiva das relações entre trabalho, poder, organizações e instituições, subjetividade, coletivo de trabalho, produção de adoecimento e/ou saúde, em uma vertente político-social e clínica.

Reconhecidas tanto por defender a centralidade social e psíquica do trabalho, como por investigar as manifestações e origens do sofrimento nas situações laborais, as clínicas do trabalho buscam também subsidiar a promoção e a preservação da saúde dos trabalhadores, por meio da transformação da realidade de trabalho (Bendassolli, \& Soboll, 2011). Trata-se, pois, não apenas de elucidar as situações nas quais o sentido do trabalho alienado ou imposto se transforma em fonte de adoecimento, mas também de compreender as relações integradas entre atividade e realização humana.

Compreendendo o trabalho para além de sua institucionalização econômica, ou seja, o emprego formal, buscamos articular pontos de vista de três abordagens clínicas do trabalho: a Clínica da Atividade, a Ergologia e a Psicossociologia do Trabalho. Vale aqui relembrar a distinção entre os conceitos ergonômicos de trabalho prescrito, aquele que é determinado pela organização ao funcionário, e trabalho real, ou seja, o trabalho tal como é concretamente realizado (Guérin, Kerguelen, Laville, Daniellou, \& Duraffourg, 2001). Dessa forma, presume-se que o sujeito se apropria da tarefa prescrita e a transforma, através de uma atividade que mobiliza sua personalidade, sua iniciativa e criatividade, inventando novos meios para executar o trabalho.

Assim, o que entendemos por trabalho é uma atividade criativa e "dirigida, ao mesmo tempo, pelo sujeito, pela tarefa e para os outros" (Clot, 2010, p. 144). Numa ótica mais ampla, Schwartz (2011) refere-se à tendência humana em renormalizar o meio em que se vive. Ela seria universal e estaria intrinsecamente ligada à nossa tentativa de viver em saúde, algo que se opõe à estrita conservação de si mesmo e à simples ausência de doença.

Por outro lado, dada a imprevisibilidade das situações de trabalho e ao vazio de normas a ser preenchido pelo trabalhador na atividade realizada, já que o prescrito nunca esgota as possibilidades da realidade, Schwartz (2011) e Clot (2010) reforçam a importância do coletivo de trabalho. Com efeito, a emergência de normas e sentidos no trabalho ocorre de forma individual e coletiva, como algo transitório e que se constrói no próprio desenrolar da atividade, segundo 
a maneira como os trabalhadores percebem e agem, frente às suas tarefas.

Os pressupostos acima apontam para elementos que nortearam nossa pesquisa, tais como: observar a atividade de trabalho, em seu contexto organizacional e institucional; ouvir seus protagonistas, individual ou coletivamente; levantar os desafios que se apresentam aos trabalhadores, no espaço entre o prescrito e o real; considerar o fazer humano além de sua institucionalização econômica, compreendendo-o como fonte de sentido e poder de ação sobre si mesmo e sobre o mundo; e, por fim, apreender o trabalho em sua dimensão coletiva.

A seguir, descrevemos o método utilizado em nossa investigação.

\section{Método}

Nossa pesquisa qualitativa, do tipo estudo de caso (Pires, 2010), buscou não só investigar as especificidades do estabelecimento em questão, mas possibilitar a compreensão de outros fenômenos que possam ocorrer em espaços semelhantes de confinamento. Privilegiou-se assim o uso de dispositivos que convocassem os próprios sujeitos a refletir sobre suas práticas (Bendassolli, \& Soboll, 2011).

O presente estudo, como já apontado, foi conduzido no manicômio judiciário de Barbacena, hoje chamado HPJJV. Atualmente, ele possui capacidade para cerca de 160 homens e 50 mulheres e recebe pacientes de todo o estado de Minas Gerais, abrigando um pavilhão masculino e outro feminino. Em janeiro de 2017, $63 \%$ de sua população geral estava em cumprimento de medida de segurança; $22 \%$ aguardando exames de sanidade mental, cessação de periculosidade ou dependência toxicológica; e $15 \%$ submetida a tratamento psiquiátrico temporário.

Além de agentes, servidores administrativos e auxiliares, o HPJJV conta com uma equipe de atendimento multidisciplinar. São eles os responsáveis diretos pelos serviços envolvidos na garantia do direito de cidadania à população presa. No total, a instituição tem 187 trabalhadores, sendo 119 agentes - 98 homens e 21 mulheres - e 68 funcionários de formação técnica ou nível superior, que compõem o setor administrativo e técnico, conforme o Quadro 2.

O estudo de campo foi desenvolvido no período de abril a setembro de 2017, com oito visitas ao estabelecimento, entre os meses de abril a setembro. Consideramos como ferramentas para a produção
Quadro 2

Relação de funcionários do Hospital Psiquiátrico e Judiciário Jorge Vaz por cargo.

\begin{tabular}{|lc|}
\hline Cargo & Servidores \\
\hline $\begin{array}{l}\text { Agente de Segurança Penitenciário } \\
\text { (homens) }\end{array}$ & 98 \\
$\begin{array}{l}\text { Agente de Segurança Penitenciário } \\
\text { (mulheres) }\end{array}$ & 21 \\
Administrativo & 24 \\
Técnico de Enfermagem & 14 \\
Enfermeiro & 2 \\
Médico Clínico & 5 \\
Médico Psiquiatra & 6 \\
Psicólogo & 5 \\
Terapeuta Ocupacional & 2 \\
Auxiliar de Consultório Dentário & 2 \\
Dentista & 1 \\
Farmacêutico & 1 \\
Gerente de Produção & 1 \\
Pedagogo & 1 \\
Analista Técnico Jurídico & 2 \\
Assistente Social & 2 \\
Total & 187 \\
\hline
\end{tabular}

Fonte: Elaborado pelo autor, a partir de dados disponibilizados pelo Hospital Psiquiátrico e Judiciário Jorge Vaz, em 5 de dezembro de 2017.

de nosso material empírico: entrevistas individuais, observação participante, análise documental, diários de campo e conversas informais, individuais ou coletivas, no próprio posto de trabalho.

A investigação foi centrada no pavilhão masculino, observando e anotando as atividades dos agentes penitenciários masculinos, no interior e no exterior das galerias. Tal critério foi adotado, devido à maior quantidade de agentes e de presos do sexo masculino. Abaixo caracterizamos cada um dos 10 trabalhadores entrevistados:

Foram entrevistados, formalmente, nove agentes masculinos e um profissional de Psicologia. As entrevistas foram gravadas em áudio e transcritas. A seleção dos participantes ocorreu de forma 
Quadro 3

Caracterização dos trabalhadores entrevistados.

\begin{tabular}{|lcccc|}
\hline Entrevistado & Cargo & Tempo de trabalho na & Tempo de atuação no & $\begin{array}{c}\text { Experiência em } \\
\text { unidade prisional } \\
\text { comum }\end{array}$ \\
\hline S01 & SEAP & HPJJV & Não \\
S02 & Agente & 29 anos & Não anos & Sim \\
S03 & Agente & 35 anos & 35 anos & Sim \\
S04 & Agente & 8 anos & 4 anos & Não \\
S05 & Agente & 2 anos e 5 meses & 1 ano e 2 meses & Sim \\
S06 & Agente & 39 anos & 39 anos & Não mencionou \\
S07 & Agente & 2 anos e 3 meses & 1 ano e 4 meses & Sim \\
S08 & Agente & Não mencionou & Não mencionou & Sim \\
S09 & Agente & 10 anos & 6 anos & Sim \\
S10 & Psicólogo & 9 anos & 2 anos & \\
\hline
\end{tabular}

SEAP: Secretaria de Estado de Administração Prisional.

Fonte: Elaborado pelo autor com base na pesquisa de campo.

variada, ora por indicação da direção, ora por interesse espontâneo em participar da pesquisa ou por sugestão dos próprios entrevistados. Além das entrevistas, conversas informais ocorreram, em diferentes momentos, com os diretores geral e de segurança do HPJJV, além de outros trabalhadores, nos moldes da observação participante.

Para a análise dos dados, seguimos as três fases da análise de conteúdo, descritas por Bardin (1977): a pré-análise; a exploração do material; o tratamento dos resultados, a inferência e a interpretação.

A partir do material produzido, procedeu-se à codificação e à categorização, com a utilização do software ATLAS.ti 8, desenvolvido para análise qualitativa de dados, buscando-se a formulação de hipóteses e interpretações.

\section{Resultados e discussão}

A atividade do agente de segurança penitenciário, em uma prisão ou em um hospital de custódia e tratamento psiquiátrico, é complexa, desenvolvendo-se em diversos locais, situações e modalidades, no interior e no exterior das celas. Ele as vigia de variadas distâncias, abrindo e fechando-as. Pode-se dizer que, em toda atividade na qual o preso está envolvido, o agente aí também está. Cabe destacar que ele, nessa instituição, refere-se frequentemente ao indi- víduo acautelado como "preso-paciente", termo que utilizaremos daqui em diante, em alguns trechos.

No HPJJV, os agentes estão divididos em diaristas e plantonistas. Os primeiros atuam de segunda a sexta-feira, cumprindo 40 horas semanais. Já os plantonistas, divididos em quatro equipes, atuam no regime de 24 horas trabalhadas por 72 de descanso. Cada equipe de plantonistas é coordenada por um inspetor e um subinspetor, e todos os agentes respondem hierarquicamente ao diretor de segurança.

Em síntese, o agente realiza as seguintes atividades: recepção e cadastro dos visitantes e profissionais; revista de familiares que visitam os presos, vistoria dos alimentos e pertences trazidos por eles; acompanhamento dos atendimentos técnicos recebidos pelo preso, como no caso da Psicologia, do serviço social e enfermagem, por exemplo; acompanhamento das aulas às quais o preso comparece, na escola da unidade; vigilância do trabalho realizado pelo preso, na faxina, na horta ou na lavanderia da unidade.

O agente exerce ainda a escolta, na transferência de presos para outros presídios, para audiências jurídicas, atendimento médico ou internações em unidades de saúde externas; vigilância nas guaritas da unidade; segurança e ronda nas galerias onde estão localizados os dormitórios e as celas individuais; entrega de café, lanche, almoço e jantar aos presos; acompanhamento da distribuição da medicação 
prescrita pela equipe de saúde; acompanhamento do banho de sol; atividades administrativas inerentes à equipe de segurança, como organização de viaturas e dos profissionais para escoltas, escalas de trabalho, registros e atualizações em sistema informatizado, emissão e recebimento de documentos.

A respeito dessas múltiplas atribuições, o agente julga ir além de suas atividades prescritas, principalmente em função do estatuto ambíguo do interno, louco e infrator. Alguns trechos das entrevistas ilustram esta situação. Os agentes são aqui identificados conforme caracterização do Quadro 3: "Aqui no hospital, o agente penitenciário não é responsável apenas pela segurança, que é o que a gente vê, quando a gente tá lotado em um presídio [convencional], né? Aqui ele acaba se envolvendo em outras atividades, além da segurança" (S03). Para outro trabalhador:

"Meu amigo, o trabalho do agente aqui é psicólogo, psiquiatra, médico, enfermeiro, como se diz, é, analista, o trabalho da gente aqui é esse [...] O cara é tudo ao mesmo tempo, então uma hora você é psicólogo, uma hora você é psiquiatra, e assim vai" (S07).

A seguir, discutimos quatro categorias escolhidas para a análise da atividade do agente. A primeira delas refere-se à escolha da profissão e à representação da atividade.

\section{“Quando eu vim pra cá, eu não sabia que aqui era assim"}

Quanto à escolha da profissão, foi possível notar uma variável relacionada à época de entrada do trabalhador na SEAP e no HPJJV. Entre os agentes com mais de 30 anos no manicômio judiciário, observou-se a predominância da "necessidade", como fator primordial para a escolha da profissão. Já entre trabalhadores que ingressaram em um período inferior a quinze anos, ou seja, após a regulamentação da carreira, o interesse pela estabilidade garantida pelo serviço público e o salário alto, em relação ao nível médio de escolaridade exigido, são os principais motivadores. Todavia, o desconhecimento do que seria o trabalho realizado naquele local foi quase unânime. Vejamos um exemplo:

A oportunidade de ter uma profissão com cargo efetivo, ter uma segurança. Também pelo salá- rio. A profissão em si eu não a conhecia tão bem assim, eu fazia ideia do que fazia, mas não conhecia a complexidade do cargo, todas as peculiaridades do cargo [...] e acredito que boa parte das pessoas que escolheram essa profissão seja por isso também (S04).

Apesar disso, todos afirmaram gostar da profissão ou se identificar com a carreira, e que fariam essa escolha de novo, se fosse o caso. Afinal, em sua visão, predomina a representação bastante positiva do que fazem, embora esteja clara para eles a representação social negativa do seu ofício e da própria instituição:

De um modo geral, é um trabalho estressante e interessante. Porque quando você tem mesmo o dom de cuidar de alguém é quase uma dádiva né? Querer que a pessoa fique bem, fique tranquila, fique... cuidada mesmo. É um serviço muito delicado, sabe? É um serviço precioso (S02).

Na maior parte do tempo os agentes são esquecidos, ainda é uma profissão malvista pela sociedade. Quem tá aqui tá também abandonado, até pela família. A sociedade tem a visão do agente relacionado com a coerção. $O$ trabalho dos agentes não é um trabalho conhecido (S03).

Apesar da identificação com o ambiente da prisão, do preso e da profissão como algo desvalorizado socialmente - como nos termos do "trabalho sujo" e do "negativo psicossocial", evocados anteriormente - fica evidente que o sentido atribuído pelos agentes ao próprio ofício implica uma imagem positiva do mesmo.

Observou-se ainda que, ao identificar sua atividade com as atribuições do "cuidar", os agentes se apropriam da noção de cuidado como um contraponto ou um elemento extra que eles conferem a um trabalho fundamentalmente marcado pela repressão, dando-lhe significados morais - "uma dádiva", "um serviço muito delicado" - que o enaltecem, ao invés de desmerecê-lo. Afinal, o trabalho "humanizado", diferente do executado nas prisões convencionais, no relacionamento com os presos-pacientes, é o que possibilita aos agentes atribuir grande valor moral à sua profissão. 


\section{"Um médico aqui do hospital fala que nós somos agentes penitenciários terapêuticos"}

Como visto, o cuidado e a relação humanizada com os presos-pacientes diferenciam o trabalho do agente, no HPJJV, do que ocorre em uma prisão convencional. Apesar de não fazermos aqui um estudo comparativo com o trabalho dos agentes de prisões tradicionais, a revisão de literatura mostra que o elemento "cuidado" não se encontra comumente vinculado ao trabalho do agente penitenciário, enquanto profissão (Bezerra, Assis \& Constantino, 2016). A fala de um dos participantes é esclarecedora, a esse respeito: "É diferente, sabe? Requer uma atenção. Requer carinho. Mesmo que você não tenha esse carinho, mas você consegue captar ele, sabe? Aplicar ele com a convivência com os pacientes" (S02).

Neste mesmo viés, o preso veria o agente do manicômio judiciário como um "amigo", não um "inimigo", como ocorre em uma prisão convencional.

É totalmente diferente porque acaba que o tratamento é mais humano. Aqui a gente tem um contato mais próximo com o paciente, eles têm um contato mais próximo com a gente. No presídio parece que tem mais uma animosidade, eles conversam menos com os agentes, aqui você vê que o tratamento é diferenciado (S10).

Essa peculiaridade do cuidado é evocada por Goffman (2015), para quem o fato de os pacientes tornarem-se objeto de afeto ou vínculo emocional é comum em "instituições totais", já que se lida com seres vivos, não com objetos inanimados.

Paciência e compreensão são elementos que, de certa forma, caracterizam "a postura esperada" do agente no HPJJV, fazendo da empatia, ou seja, a capacidade de se colocar no lugar do outro, um elemento indispensável para ele. Com efeito, a convivência rotineira com os presos-pacientes faz com que o discernimento, que se manifesta nos olhares, gestos e diálogos, se torne seu principal instrumento de trabalho, permitindo-lhe saber como e quando agir, em cada situação e com cada paciente: "Mais na conversa, na conversa, aqui tudo é na conversa. Em todo lugar que eles usam calibre 12 para resolver o problema dos caras, a gente aqui chega lá e conversa, entra lá e tenta dialogar com o cara" (S08).
Esse tipo de postura é confirmado por outro participante da pesquisa:

"Aqui você precisa ter aquela sensibilidade para poder analisar melhor, assim, a situação do preso, e poder resolver da melhor forma" (S04).

Verificou-se que munir-se dos instrumentos disponíveis - o diálogo, o café, o cigarro, ou seja, o próprio vínculo estabelecido com o preso-paciente - é o que permite acessar o estado físico e mental dos presos e se relacionar com eles, garantindo a ordem e a segurança do estabelecimento. Aqui também fica evidente que, em sua atividade, o agente se vê frente a frente com um debate de normas e valores, como afirma Schwartz (2011), o que parece ser afirmado pelo coletivo do ofício:

[...] no qual circulam, implicitamente, saberes e normas endógenas, resultando em compartilhamento de valores, é a condição sine qua non tanto para uma certa eficácia quanto para uma vida aceitável no trabalho [...] aí se desenvolvem o gosto, a saúde, uma certa potência de ser no trabalho (p. 147).

O autor acrescenta que esse debate de normas e valores implica uma escolha do uso de si que se renova constantemente, por meio de arbitragens que visam ao bem comum local e que "às vezes podem desenvolver prodigiosamente a eficácia de um meio de trabalho" (p. 147). Vejamos mais um depoimento:

Eu sempre falei na cabeça deles, sabe: mão pra trás aqui não tem, é assim e assim e assado, vai devagar, vai mais na conversa, toma um cafezinho, acende o cigarro do cara, tá entendendo. Cativa o cara para seu lado, puxa a confiança do paciente, paciente é confiança, que ele vai te respeitar. E você ganha a pessoa assim (S02).

Todavia, privilegiar essa postura em detrimento da coação corporal e da repressão, por exemplo, não é um comportamento unânime, entre os agentes do HPJJV. Alguns deles reprovam ou consideram inútil esse tratamento ao preso portador de sofrimento mental, como mostraremos a seguir. 


\section{"Aqui a gente não fala preso, a gente fala paciente"}

Apesar de os agentes se referirem ao cuidado, nossa pesquisa deixou evidente a ambivalência do HPJJV, quanto ao tratamento dispensado aos presos-pacientes. Isso ficou evidenciado ao primeiro olhar, na própria estrutura física do estabelecimento, assim como em nossas observações sobre o seu funcionamento cotidiano. A lógica da segurança e da disciplina está presente, antes de tudo, na restrição do direito de ir e vir, nas algemas, no confinamento, na maioria numérica dos agentes de segurança, em relação aos demais profissionais, e na própria gestão da instituição, nas mãos do sistema estadual de justiça, não do sistema de saúde.

Constatou-se que o conflito entre os modelos "hospital" e "prisão" está presente não só nos modos de lidar e se relacionar com o preso, mas no discurso de alguns agentes. A alternância entre nomenclaturas, tais como "preso", "paciente" ou "preso-paciente", foi constante, na fala dos agentes, cujo contato com os internos é permanente, conforme se vê a seguir: "Tudo que se refere ao preso, aqui a gente não fala preso, a gente fala paciente, tudo que se refere a assuntos da vida do paciente, o agente está envolvido" (S02).

Contudo, o discurso que ressalta o "tratamento diferenciado" não é universal: "Para mim, não é bem paciente, é mais é preso [...] porque você tratar todo mundo como paciente, eu não acho que é muito seguro" (S04).

Quanto ao próprio nome dado às estruturas do HPJJV, um agente sinaliza a incoerência que lhe é inerente:

Aqui a gente fala pavilhão, né? Como em uma unidade comum. A diferença é que aqui a gente não usa o nome cela, a gente usa o nome enfermarias, que são, nada mais do que celas maiores, né? Sem superlotação, cada paciente tem a sua cama e a gente fala enfermaria, a gente não fala cela aqui (S03).

Como se vê, ainda que, a partir da entrada do preso no HPJJV, ele seja considerado um paciente, existem diferentes representações e posturas dos agentes, em relação a ele. Isso tem uma influência direta na rotina do estabelecimento. Segundo o psicólogo entrevistado, o resultado de seu trabalho só é efetivo, se o agente permitir:
É, todo o trabalho médico, psicológico, social, espiritual, ocupacional, laboral, escolar, vai ter um bom resultado se o agente penitenciário quiser. $\mathrm{O}$ agente penitenciário tem um poder de ser essa pessoa que está 24 horas com o interno, ele pode, ele tem um poder maior de ajudar na progressão do tratamento dessa pessoa ou fazer corpo mole e esse tratamento não ir muito adiante (S09).

Os agentes são, pois, incumbidos de acompanhar e conduzir o preso aonde ele for, mantendo-o vigiado em tempo integral, seja no consultório médico, na lavanderia, na horta ou em sua própria cela. Isso mostra que cabe à equipe de segurança determinar "o que pode" e "o que não pode" na rotina da instituição. Em outras palavras, o HPJJV funciona, prioritariamente, como um estabelecimento de segurança, não de saúde. Como, então, a convivência com essa realidade afeta os agentes que mantêm contato direto e frequente com o preso, no corpo a corpo, no mesmo ambiente? É o que tratamos a seguir.

\section{"Não vou falar que eu estou cansado fisicamente, estou cansado mentalmente, sabe?"}

Os riscos do trabalho nas prisões são elementos comumente discutidos, como demonstram as pesquisas de Oliveira, Silva Junior, Costa e Araújo (2017) e Figueiró (2015), por exemplo. Além dos riscos físicos e da ameaça real à integridade física e à própria vida, os agentes penitenciários estão também sujeitos aos riscos psicossociais. As atividades laborais nas prisões figuram entre as mais desgastantes e estressantes do mundo (Brasil, 2015).

No caso do manicômio judiciário, constatou-se que o perigo físico se encontra relativamente diminuído e que o impacto da atividade no indivíduo se revela principalmente na assimilação, por contágio ou influência, de comportamentos dos pacientes e no envolvimento afetivo com eles. Afinal, o contato frequente com discursos que circulam entre a realidade e o delírio implica uma exigência psicológica maior, no exercício do ofício:

Num hospital psiquiátrico, exige muito mais esforço psicológico do que físico. No presídio, você trabalha com cachorro, com armamento, segurando a grade com o pé para ninguém tentar empurrar e sair correndo. Aqui já é diferente. Você não precisa ter todo aquele condiciona- 
mento físico, mas aqui você precisa ter aquela sensibilidade para poder analisar a situação do preso e resolver da melhor forma (S04).

[...] você cuidar da pessoa que tem déficit mental te dá muito trabalho... Não trabalho físico, trabalho psicológico. Então, você acaba absorvendo vícios, palavras, gestos, e sem perceber. Eu tenho medo, às vezes, de ficar louco, eu tenho medo de adquirir um déficit mental, que eu não possa ter controle das minhas atitudes, em virtude disso aqui (S02).

Para S08, "o cara às vezes se envolve muito. A cabeça do cara fica tão atribulada que ele não consegue resolver o problema de todo mundo". De acordo com S09, um profissional de Psicologia do HPJJV, a exposição a diferentes "desorganizações psíquicas" é um fator que demanda a exigência psicológica da atividade:

Eu venho aqui e fico meia hora com cada paciente. $\mathrm{O}$ agente penitenciário tá o dia inteiro com ele, 24 horas. Acompanha ali o dia inteiro. Então, deveria ter não só um treinamento para entrar, como deveria ter um acompanhamento. Não é fácil ficar 24 horas exposto a essa desorganização psíquica de uma pessoa. É exaustivo (S09).

Para Clot (2010), o objeto da atividade de cada sujeito é lugar de colisão e de trocas entre atividades, pois "o objeto é um traço de união, de saída, controverso entre os homens que trabalham" (p. 22). O objeto é um objeto-vínculo, que "está na" e "contém" a sociedade. Nessa perspectiva, a relação estabelecida com o preso foi fundamental para compreendermos a atividade do agente penitenciário.

Verificou-se que o impacto do trabalho remete ao enfrentamento de uma realidade especialmente dolorosa para o agente, pelo fato de ele conviver "corpo-a-corpo" com dois sofrimentos vivenciados pelos pacientes: a privação da liberdade e o sofrimento mental, como demonstram os depoimentos a seguir: "Um amigo meu, um colega nosso aqui, deve ter te falado que você acaba pegando um apego com alguns [pacientes]. Provavelmente, pelo menos com uns, você vai ter" (S04); "Tem paciente que você olha para ele e te dá medo. Eu já olhei paciente aqui e já chorei, porque não é possível um ser humano chegar naquele ponto" (S02).
O testemunho dos participantes da pesquisa nos permite afirmar que não há como o agente penitenciário sair incólume, após cumprir a tarefa rotineira de adentrar o manicômio judiciário, lidando com a ambivalência e as contradições inerentes à sua atividade. Com efeito, esta oscila, estruturalmente, entre o controle e o cuidado, a opressão e a recuperação de sujeitos humanos, institucionalmente rotulados como portadores de loucura e condenados à privação da liberdade.

\section{Considerações finais}

No manicômio judiciário de Barbacena, um estabelecimento híbrido que, em seus quase 100 anos de história, trata não só do crime, mas de sua conjunção enigmática com a loucura, deparamo-nos com um ofício valorizado por seus protagonistas, os agentes penitenciários.

Em um contexto institucional controverso como o manicômio judiciário, entre discursos que defendem a sua existência e sua abolição (Rauter, 2016; Venturini, 2016), conhecemos pessoas que cuidam, que se dedicam, que se esforçam, mas que também vivem experiências contraditórias, que se esgotam ou, às vezes, até se acomodam, em meio à superposição complexa de dois dispositivos de controle social.

A escassez de estudos sobre os trabalhadores de manicômios judiciários revela o "esquecimento" desses trabalhadores. Embora constituam um contingente diminuto, dentro da categoria profissional de agentes penitenciários, eles têm uma função essencial e diferenciada, no acompanhamento do "louco infrator". Pacientes e trabalhadores materializam, no manicômio judiciário, o resíduo social invisível ou marginalizado, apesar das transformações já trazidas pela reforma psiquiátrica. Tal quadro sugere que o atual contexto dos manicômios judiciários, no Brasil, demanda ainda novas pesquisas.

Esperamos poder contribuir, mesmo que modestamente, com a produção de conhecimento acerca da atividade dos agentes penitenciários, em um estabelecimento que agrega elementos de uma prisão tradicional e de um hospital psiquiátrico. Conhecer o trabalho desses profissionais é também defrontar-nos com o funcionamento de um dispositivo institucional que ainda ostenta um "nó civilizatório", em sua contraditória e inconsistente solução para as complicadas tramas do crime e da loucura. 


\section{Referências}

Azevedo, K. R. N. (2014). E aí as histórias ficam boas: Sobre a implantação dos Serviços Residenciais Terapêuticos em Barbacena/MG (Dissertação de mestrado). Programa de Pós-Graduação em Psicologia, Universidade Federal de São João Del Rei, São João Del Rei, MG, Brasil.

Bardin, L. (1977). Análise de conteúdo. Lisboa: Edições 70.

Bendassolli, P. F., \& Soboll, L. A. (2011). Clínicas do trabalho: Filiações, premissas e desafios. Cadernos de Psicologia Social do Trabalho, 14(1), 59-72.

Bezerra, C. M., Assis, S. G., \& Constantino, P. (2016). Sofrimento psíquico e estresse no trabalho de agentes penitenciários: Uma revisão da literatura. Ciência \& Saúde Coletiva, 21(7), 2135-2146. https://doi.org/10.1590/141381232015217.00502016

Brasil. (2014). Serviço de avaliação e acompanhamento de medidas terapêuticas aplicáveis à pessoa com transtorno mental em conflito com a lei. Brasília, DF: Ministério da Saúde.

Brasil. (2015). Plano Nacional de Política Criminal e Penitenciária. Brasília, DF: Ministério da Justiça.

Brasil. (2017). Levantamento nacional de informações penitenciárias - INFOPEN. Brasília, DF: Departamento Penitenciário Nacional.

Câmara, L. (2017, outubro 29). Corte de agentes penitenciários ameaça presídios em Minas Gerais: Saída de 1.800 contratados até dezembro vai deixar desfalcadas unidades prisionais. O Tempo, Cidades, Segurança Pública. Recuperado de http://www.otempo.com.br/cidades/corte-de-agentes-penitenci\%C3\%Alrios-amea\%C3\%A7a-pres\%C3\%ADdios-em-minas-gerais-1.1536703

Carrara, S. (1998). Crime e loucura: O aparecimento do manicômio judiciário na passagem do século. Rio de Janeiro, RJ: EdUERJ.

Carrara, S. (2010). A história esquecida: Os manicômios judiciários no Brasil. Journal of Human Growth and Development, 20(1), 16-29. https://doi.org/10.7322/jhgd.19939

Clot, Y. (2010). Trabalho e poder de agir. Belo Horizonte, MG: FabreFactum.

Conselho Federal de Psicologia - CFP. (2015). Inspeções aos manicômios: Relatório Brasil 2015. Brasília, DF: o autor.

Conselho Federal de Psicologia - CFP. (2016). Louco infrator e o estigma da periculosidade. Brasília, DF: o autor.

Conselho Regional de Medicina do Estado de São Paulo - CREMESP. (2013). Medida de segurança: uma questão de saúde e ética. São Paulo, SP: o autor.

Decreto no 1.132, de 22 de dezembro de 1903. Reorganiza a assistência a alienados. Diário Oficial da União, 24 dez. 1903.

Decreto No 7.471, de 31 de janeiro de 1927. Aprova o regulamento da assistência a alienados de Minas Gerais. Minas Gerais, BeloHorizonte. Recuperadodehttps://www.lexml.gov.br/urn/urn:lex:br;minas.gerais:estadual:decreto:1927-01-31;7471

Decreto No 47.087, de 23 de novembro de 2016. Dispõe sobre a organização da Secretaria de Estado de Administração Prisional. Recuperado de https://www.almg.gov.br/consulte/legislacao/completa/completa-nova-min. html?tipo=DEC\&num $=47087 \&$ comp $=\& a n o=2016 \&$ texto $=$ original

Decreto-lei No 2.848, de 7 de dezembro de 1940. Código Penal. Diário Oficial da União, 3 jan. 1941.

Diniz, D. (2013). A custódia e o tratamento psiquiátrico no Brasil: Censo 2011. Brasília, DF: Letras Livres.

Diniz, D., \& Brito, L. (2016). "Eu não sou presa de juízo, não": Zefinha, a louca perigosa mais antiga do Brasil. História, Ciências, Saúde, 23(1), 113-129. https:/ /doi.org/10.1590/S0104-59702016000100008

Figueiró, R. A. (2015). Cartografia do trabalho de agentes penitenciários: Reflexão sobre o "dispositivo prisão" (tese de doutorado). Centro de Ciências Humanas, Letras e Artes, Universidade Federal do Rio Grande do Norte, Natal, RN, Brasil.

Foucault, M. (1972). A história da loucura na idade clássica. São Paulo, SP: Perspectiva.

Foucault, M. (2014). Vigiar e punir: Nascimento da prisão (42a ed.). Petrópolis, RJ: Vozes.

Goffman, E. (2015). Manicômios, prisões e conventos (9a ed.). São Paulo, SP: Perspectiva.

Guerin, F., Kerguelen, A.. Laville, A., Daniellou, F., \& Duraffourg, J. (2001). Compreender o trabalho para transformá-lo: A prática da ergonomia. São Paulo, SP: Fundação Vanzolini. 
Hughes, E. (1996). Le regard sociologique: Essais choisis. Paris: Ehess.

Instituto de Pesquisa Econômica Aplicada-IPEA (2015). Reincidência criminal no Brasil: Relatório de pesquisa. Rio de Janeiro, RJ, o autor. Recuperado de http://www.cnj.jus.br/files/conteudo/destaques/arquivo/2015/07/572bba385357003379ffeb4c9aalf0d9.pdf

Lei No 7.210, de 11 de julho de 1984. Institui a Lei de Execução Penal. Diário Oficial da União, 13 jul. 1984.

Lei No 10.216, de 6 de abril de 2001. Dispõe sobre a proteção e os direitos das pessoas portadoras de transtornos mentais e redireciona o modelo assistencial em saúde mental. Diário Oficial da União, 9 abr. 2001.

Lei No 14.695, de 30 de julho de 2003. (Cria a Superintendência de Coordenação da Guarda Penitenciária, a Diretoria de Inteligência Penitenciária e a carreira de Agente de Segurança Penitenciário e dá outras providências. Minas Gerais Diário do Executivo, 28 ago. 2003.

Lhuilier, D. (2014). Introdução à psicossociologia do trabalho. Cadernos de Psicologia Social do Trabalho, 17(spe), 5-20. https://doi.org/10.11606/issn.1981-0490.v17ispelp5-19

Lima, M. E. A. (2011). Abordagens clínicas e saúde mental no trabalho. In: P. F. Bendassolli, \& L. A. Soboll, (Orgs.) Clínicas do trabalho: Novas perspectivas para a compreensão do trabalho na atualidade (pp. 227-253). São Paulo, SP: Atlas.

Minas Gerais. Secretaria de Estado de Defesa Social. (2013). Regulamento do Curso de Formação Técnico-Profissional. Edital SEPLAG/SEDS no 08/2013. Recuperado de http://fs.esppconcursos.com.br/arquivos/a5a6732656ab06ec5150e8616a917a6e.pdf

Ministério Público. Conselho Nacional do Ministério Público. (2016). A visão do Ministério Público sobre o sistema prisional brasileiro - 2016. Brasília, DF: o autor.

Oliveira, A. R. M. O., Silva Junior, E. J., Costa, E. C. P., \& Araújo, E. I. M. D. (2017). A prisionização de agentes penitenciários e seus efeitos sobre a função reintegradora da pena privativa de liberdade. In: F. Fidalgo, \& N. Fidalgo, (Orgs.). Sistema prisional: Teoria e pesquisa. (pp. 255-278). Belo Horizonte, MG: Editora UFMG.

Oliveira, V. N., Ribeiro, L. M., Bastos, L. M. (2015). Os agentes penitenciários em Minas Gerais: Quem são e como percebem a sua atividade. Sistema Penal \& Violência, 7(2), 175-192.

Pacheco, J. A. (2011). O Hospital de Custódia e Tratamento Psiquiátrico: Revisão dos estudos brasileiros (Monografia). Departamento de Serviço Social, Universidade de Brasília, Brasília, DF, Brasil.

Pessotti, I. (2006). Sobre a teoria da loucura no século XX. Temas em Psicologia, 14(2), 113-123.

Pires, A. (2010). Amostragem e pesquisa qualitativa: Ensaio teórico e metodológico. In: J. Poupart, J. Deslauriers, L. Groulx, A. Laperrière, R. Mayer, A. P. \& Pires. (Orgs.), A pesquisa qualitativa: Enfoques epistemológicos e metodológicos (2a ed., pp. 154-211). Petrópolis, RJ: Vozes.

Rauter, C. (2016). Por que o manicômio ainda existe? In Conselho Federal De Psicologia - CFP, Louco infrator e o estigma da periculosidade. Brasília, DF: o autor.

Schwartz, Y. (2011). Manifesto por um ergoengajamento. In: P. F. Bendassolli, \& L. A. Soboll. (Orgs.), Clínicas do trabalho: Novas perspectivas para a compreensão do trabalho na atualidade (pp. 132-166). São Paulo, SP: Atlas.

Secretaria de Estado de Administração Prisional - SEAP. (2016). Regulamento de Normas e Procedimentos do Sistema Prisional de Minas Gerais - ReNP. Belo Horizonte, MG: o autor.

Sindicato dos Agentes de Segurança Penitenciária de Minas Gerais - SINDASP. (2017). Institucional. História. Recuperado a partir de http://www.sindaspmg.org.br/sindasp/institucional

Venturini, E. (2016). Manicômios judiciários: Uma saída. In: Conselho Federal de Psicologia - CFP, Louco infrator e o estigma da periculosidade. Brasília, DF: o autor.

\section{Rodrigo Padrini Monteiro}

Psicólogo, Mestre e Doutorando em Psicologia pela Pontifícia Universidade Católica de Minas Gerais, Belo Horizonte - MG. Brasil.

E-mail: rodrigopadrini@gmail.com

(iD https:// orcid.org/0000-0002-7153-2448 
José Newton Garcia Araújo

Psicólogo, Doutor em Psicologia Clínica e Social, Universidade de Paris VII, França. Pesquisador do CNPq. Professor dos programas de graduação e de Pós-graduação em Psicologia da Pontifícia Universidade Católica de Minas Gerais, Belo Horizonte-MG. Brasil.

E-mail: jinga@uol.com.br

(iD https://orcid.org/0000-0001-9648-9741

Endereço para envio de correspondência:

Rua Levindo Lopes, 52, apto 703, Savassi, Belo Horizonte, MG, Brasil. CEP 30140-170

Recebido 16/08/2018

Aprovado 23/08/2018

Received $08 / 16 / 2018$

Approved 08/23/2018

Recibido 16/08/2018

Aceptado 23/08/2018

Como citar: Monteiro, R. P.; \& Araújo, J. N. G. (2018). Manicômio Judiciário e Agentes Penitenciários: entre Reprimir e Cuidar. Psicologia:Ciênciae Profissão,38(n.spe.2), 144-158.https://doi.org/10.1590/1982-3703000211962

How to cite: Monteiro, R. P.; \& Araújo, J. N. G. (2018). Judicial Asylums and Prison Guards: Between Repressing and Caring. Psicologia: Ciência e Profissão, 38(n.spe.2), 144-158. https://doi.org/10.1590/1982-3703000211962

Cómo citar: Monteiro, R. P.; \& Araújo, J. N. G. (2018). Manicomio Judicial y Agentes Penitenciarios: entre Reprimir y Cuidar. Psicologia: Ciência e Profissão, 38(n.spe.2), 144-158. https://doi.org/10.1590/1982-3703000211962 